\title{
El juego de ecos y espejos: un acercamiento al estudio de la dilogía en la obra poética de Xavier Villaurrutia
}

\author{
Gloria Estela Baez Pinal
}

La autora busca en este trabajo ilustrar, mediante una serie de ejemplos, la predilección de Villaurrutia hacia la dilogía, figura retórica presente en sus juegos de palabras, bien a través de la disemia o polisemia, ya mediante la homonimia. Pese a que en algunos casos el resultado no es del todo afortunado, en la mayoría, el poeta logra alcanzar la calidad y originalidad por él deseada; logrando que los significados o formas del contenido se propaguen a manera de espejos y las formas de la expresión o significantes se conviertan ante esta multiplicidad en ecos incesantes.

In this paper the author shows with a series of examples, Villaurrutia's particular taste for dilogy, a rhetorical figure present in his play upon words, through disemy and polisemy as well as homonymy. Although in some cases the result is not completely fortunate, in most of them the poet is able to obtain the quality and originality he seeks, and succeeds in spreading the meanings and forms of content like mirrors and, due to this multiplicity, the forms of expression or signifiers become incessant echoes. 
Gloria Estela Baez Pinal*

\title{
El juego de ecos y espejos: un acercamiento al estudio de la dilogía en la obra poética de Xavier Villaurrutia
}

\author{
A César Rodríguez Chicharro, \\ a veinte años de su ausencia física
}

La dilogía, ${ }^{1}$ define Helena Beristáin, es el "tropo de dicción que consiste en repetir una palabra disémica -que posee dos significados - dándole en cada una de dos posiciones, o en una misma, un significado distinto", y precisa: "se relaciona con el juego de palabras, y se funda en la homonimia y la polisemia de éstas, es decir en que la unicidad de su forma se acompaña con la pluralidad de su significado"; finalmente, considera que esta figura se utiliza con frecuencia en la literatura "porque rompe el equilibrio existente entre el significado y el significante del signo linguístico por lo que, amén de hacer denso y conceptuoso el estilo, le procura ambigüedad, que es una marca que revela la función poética de la lengua".

Tal multiplicidad significativa, motor fundamental de juegos de palabras y neologismos, así como de la creación de

* Instituto de Investigaciones Filológicas, UNAM.

1 También llamada equívoco, diáfora, anfibología, disemia, polisemia, antanaclasis, entre otros.

${ }^{2}$ Beristáin, Diccionario de retórica y poética, pp. 153-154. 
nuevas acepciones ha sido utilizada con cierta frecuencia en la literatura en lengua española. Abundan los ejemplos en la obra de Quevedo, Gracián, Góngora y Sor Juana Inés de la Cruz, por citar a los más relevantes, y constituye un recurso habitual en la poesía (sin dejar de estar ausente en la obra ensayística y dramática) de Xavier Villaurrutia, integrante del por él mismo designado "grupo sin grupo", Los Contemporáneos. ${ }^{3}$

Este autor mexicano con plena conciencia de la importancia que alcanzan dentro de su quehacer literario tales juegos, motivo de repetidos elogios así como de abundantes críticas por parte de los estudiosos de su poesía, en la carta dirigida a Bernardo Ortiz de Montellano - intitulada Una botella al marjustifica y explica su atracción hacia ellos, admitiendo que "juego, entonces, con fuego y a riesgo de quemarme". 4

De su no muy extensa obra poética, Alí Chumacero distingue tres momentos:

Pasados los titubeos iniciales se hace patente su predilección por el engaño del juego - de palabras y de ideas- que llega a confundirse con la inteligencia. Posteriormente, en su mejor época creadora, la emoción se somete a la estricta vigilancia de las facultades intelectuales, en un justo equilibrio, que lo hizo escribir sus más hondos poemas; y en la etapa final, la emoción se sobrepone a la inteligencia con tal ímpetu que lo obliga a restringir su ejercicio sólo a la superficie de las formas métricas. 5

${ }^{3} \mathrm{Si}$ bien es innegable la influencia que la literatura española tuvo en su obra, según las palabras del propio autor, el uso de los juegos de palabras en su poesía refleja una adicción mayor a la literatura francesa que a la española; es plenamente conocido su gusto por los simbolistas y vanguardistas franceses: André Gide, Paul Valéry, Jean Cocteau; y su afición por las letras italianas modernas sobre todo las de Pirandello y Botempelli (rasgo éste que lo distingue de sus compañeros de generación).

4 Villaurrutia, "Una botella al mar", en Obras, pp. 837-841.

5 Prólogo, en Obras, XIV. 
A la primera etapa - en donde encontramos ciertos rasgos románticos, modernistas y la influencia inicial, entre otros, de López Velarde y Juan Ramón Jiménez- pertenecen una treintena de poemas y su primer libro Reflejos.

Nostalgia de la muerte es sin duda su poemario más representativo y logrado; marca su segunda etapa, en la que se palpa la influencia surrealista de la escuela francesa a la que era tan adicto. Asimismo, la lectura de Cocteau, Gide, Jules Supervielle..., por mencionar sólo a los más significativos, resulta fructífera en el espíritu de Villaurrutia: surgen ahora, en vertiginosa cascada, los juegos de palabras en los que la emoción y el intelecto - como advierte Chumacero- son elementos dominantes. La madurez del poeta permite que se rebele y que su lenguaje sea revelado en toda su plenitud: como fuerza creadora, como necesidad comunicativa, como expresión erótica, pues "en manos del poeta el lenguaje no es sólo un instrumento lógico sino también un instrumento mágico". ${ }^{6} \mathrm{Su}$ poesía cae dentro de la oscuridad de la noche (de ahí su predilección por los nocturnos). Más que de motivos sería conveniente hablar de un gran motivo: la Muerte, en torno de la cual - a manera de pequeñas lunas- giran la noche, el sueño, el miedo, el amor, la búsqueda de la propia identidad, la soledad, el insomnio, el erotismo.

La Muerte es el gran juego, el único y sólo a través del juego del lenguaje se llega a Ella... la Muerte ronda, escudriña; está encerrada en un cajón, en el tintero, en una maleta; se muestra confundida como los vidrios informes del caleidoscopio, aparece de pronto en el lecho, en el viento, en la nieve o en el mar; surge hermanada al sueño; oímos su risa en el silencio y distinguimos su rostro melancólico al asomarnos a los espejos... la Muerte está ahí; siempre acechando, esperando

6 Villaurrutia, Introducción a la poesía mexicana, citado en Blanco, Crónica de la poesía mexicana, p. 228. 
siempre. Y el poeta comprende, por fin, que si como ser mortal vivirá eternamente perseguido por Ella, como creador los papeles pueden invertirse, y en este juego vital, la Muerte se transforma en un ente tangible, estéticamente bello al que puede asir por medio de la palabra. Así, de perseguido se torna en el perseguidor que en un impulso posee a la Muerte y, al conseguir hacerla suya, la vence.

Su tercera etapa, representada por su libro último Canto a la primavera y otros poemas, nos permite observar cómo la emotividad fluye de modo espontáneo, reaparece la muerte... el amor que final e irremediablemente "nos conduce a la muerte" y surgen la duda, la angustia, el temor, los celos, y aun la ironía enmarcados, todos, en metáforas, imágenes y algunos juegos de palabras.

Xavier Villaurrutia busca y halla en la poesía -misma que define como un "juego difícil de ironía e inteligencia"- el cauce que permite proyectar su mundo, cosmos enigmático y contradictorio; angustioso y oscuro en ocasiones, próximo al humor y lleno de reflejos luminosos en otros momentos, universo creado para el cual resulta no sólo conveniente, sino incluso ineludible elegir, entre otros recursos retóricos, la dilogía, valiéndose de la incalculable riqueza que confiere al poeta la palabra, la cual bajo formas engañosas y disfraces ambiguos, - ¿o qué otra cosa es lo que nombramos homonimia y polisemia?- le permite recrear un espacio en donde los espejos y los ecos se responden interminablemente. Y aquí retomo al propio Villaurrutia:

Por algún tiempo tuve, en la poesía mexicana, un involuntario trato con los espejos. Su cara impasible y dura corregía todo lo que alcanzaba a copiar. Una noche puse un espejo frente a otro: se miraron de arriba a abajo como dos enemigos mortales. Dejé caer una frase entre ambos. Repetida por boca de los espejos, la frase cambiaba de sentido sin cambiar de forma, diabólicamente: 


\section{Y mi voz que madura \\ y mi voz quemadura \\ y mi bosque madura \\ y mi voz quema dura. ${ }^{7}$}

En este artículo me propongo ilustrar mediante una serie de ejemplos la predilección de Villaurrutia hacia la dilogía, en sus juegos de palabras, bien a través de la disemia o polisemia, ya mediante la homonimia. ${ }^{8}$ No obstante que en algunos casos el resultado no es del todo afortunado, considero que en la mayoría, el poeta logra alcanzar la calidad y originalidad por él deseada; de modo tal que los significados o formas del contenido se propaguen a manera de espejos y las formas de la expresión o significantes se tornen ante esta multiplicidad en ecos incesantes.

En su Diccionario de términos filológicos, Fernando Lázaro Carreter define polisemia y disemia, y destaca la diferencia entre ambas, distinción por supuesto obvia desde la perspectiva etimológica. La polisemia es el "fenómeno consistente en la reunión de varios significados en una palabra [...]. En caso frecuente de ser dos los significados, el fenómeno se llama disemia". Así, la polisemia es un término más amplio que incluye a la disemia, o en otras palabras, ésta es un tipo específico de aquélla. ${ }^{9}$

7 Villaurrutia, "La rosa de Cocteau", en Obras, pp. 923-925.

${ }^{8}$ El primer estudio específico sobre recursos semánticos y fónicos lo realizó César Rodríguez Chicharro en el ensayo "Disemia y paronomasia en la poesía de Xavier Villaurrutia", publicado por la Universidad Veracruzana en un número de su revista La palabra y el hombre, hace ya cuarenta años. Posteriormente, Eugène L. Moretta en La poesía de Xavier Villaurrutia alude, al ocuparse de los aspectos formales de su obra poética, a los recursos estilísticos empleados por el autor; sin embargo, se limita a reproducir ideas del citado ensayo de César Rodríguez, sin enriquecerlo o ampliarlo realmente.

${ }^{9}$ Cito también las definiciones incluidas en el Diccionario de lingüística, coordinado por Ramón Cerdá. Disemia es la "forma especial de la polisemia por la cual un lexema adquiere dos sentidos distintos. En tanto que polisemia es el "lexema dotado de diversos sentidos propios y figurados en su uso habitual". 
Mayor dificultad habrá de involucrar la distinción entre polisemia y homonimia; la última, en palabras de Helena Beristáin, "relación de identidad del significante y disparidad del significado de dos signos; en otras palabras: equivalencia de sonido de los pares de palabras que a la vez ofrecen oposición semántica" y acota: "se trata de un tipo de 'relación equívoca' - o 'no unívoca' - entre el significante y el significado de las palabras, ya que a un significante corresponden dos significados, por lo que también se le ha llamado equívoco a la homonimia, cuando su empleo da lugar a la dilogía", ${ }^{10}$ aclaración pertinente para los fines de este trabajo.

Si bien las definiciones incluidas en todos los diccionarios precisan el alcance de cada uno de los dos fenómenos, ${ }^{11}$ en la práctica tal diferenciación no siempre entraña claridad; lo cual ha propiciado no pocas confusiones, por lo que cabe entonces citar a Baldinger, quien afirma que en el plano sincrónico "la homonimia es una polisemia", por ello "dos palabras pueden sentirse como una palabra con dos significaciones, y una palabra con dos significaciones pueden sentirse como dos palabras". ${ }^{2}$

A continuación ilustro algunas de las dilogías que apárecen en la poesía de Xavier Villaurrutia. ${ }^{13}$ Distingo para ello dos grupos, el primero, conformado por frases o términos que ubicados en determinados contextos adquieren más de un significado; es decir, en la creación de estos juegos de palabras subyace la polisemia o la disemia. En gran parte de ellos constatamos que el poeta mexicano recurre a las llamadas "frases hechas" (o construcciones que nos remiten a éstas) en las cuales, a su uso común —el metafórico-, se opone y, sobre todo, impone

${ }^{10}$ Beristáin, Diccionario de retórica y poética, p. 260.

${ }^{11}$ Incluyo, como ejemplo, otra definición de homonimia: "igualdad entre dos vocablos desde el punto de vista fonológico u ortográfico, pero no semántico".

12 Baldinger, Teoría semántica, p. 43.

${ }^{13}$ Algunas de ellas ya registradas en el citado ensayo de Rodríguez Chicharro. 
como significado primario un sentido literal, para convertirlas en plurivalentes. En este grupo, el término o frase con dos o más significados distintos aparece siempre una sola vez en el poema, pero contextualizado de modo tal que en esa posición es semánticamente plurivalente.

Son casos en los cuales nuestro autor logra su propósito de ser él, el que juegue con las palabras y el resultado es, por decir lo menos, plausible.

1. En el "Nocturno de la estatua" aparece en el verso que he subrayado, la frase polisémica (en cursivas):

Soñar, soñar la noche, la calle, la escalera y el grito de la estatua desdoblando la esquina ${ }^{14}$

Jugando con la frase "doblar (en) la esquina", que implica "cambiar de dirección en cierto sentido" y el prefijo negativo des-, advertimos cómo el grito no da vuelta, es decir, permanece inmóvil en la esquina como la estatua de la que proviene. Junto con este significado tenemos otro posible: el grito es tan potente que logra "desdoblar" la esquina extendiendo las calles que la formaban. Asimismo, desdoblar significa "formar dos o más cosas por separación de los elementos que suelen estar juntos en otra", por lo que en este contexto, "el grito provoca la multiplicación de esa esquina".

2. Veamos ahora lo que ocurre en "Nocturno sueño":

\author{
$\mathrm{Y}$ al doblar la esquina \\ un segundo largo
}

14 Para este trabajo he consultado la segunda edición de Xavier Villaurrutia, Obras: poesía, teatro, prosas varias, crítica, prólogo de Alí Chumacero, recopilación de textos por Miguel Capistrán, Alí Chumacero y Luis Mario Schneider, México, Fondo de Cultura Económica, 1974 (Col. Letras Mexicanas). 
mi mano acerada

encontró mi espalda

en el cual la frase marcada permite varios significados: "al dar vuelta en la esquina", "al aumentar dos veces el tamaño de la esquina" y "al hacer que perdiera su rigidez la esquina". 15

3. El "Nocturno de la estatua", sin duda uno de sus poemas más aliterativo, ofrece dos juegos dilógicos basados en las frases hechas "en un cerrar de ojos" y "estar muerto de sueño":

Hallar en el espejo la estatua asesinada, sacarla de la sangre de su sombra, vestirla en un cerrar de ojos, acariciarla como a una hermana imprevista y jugar con las fichas de sus dedos y contar a su oreja cien veces cien cien veces hasta oírla decir: "estoy muerta de sueño"

La estatua asesinada ha sido vestida "instantáneamente", pero a este significado metafórico podemos agregar el literal: se le vistió mientras cerraba los ojos para no ver su desnudez. Asimismo, esta insólita protagonista (acaso la Muerte misma, personificada dentro del poema) "está muerta de sueño", esto es, por fin el poeta ha conseguido que ella sienta un intenso sueño tras haber contado a su oreja, del uno al cien innumerables veces, seguramente como método para que venciera el insomnio.

15 En "Nocturno sueño" doblar vuelve a aparecer como término disémico:

El cielo en el suelo como en un espejo

la calle azogada

dobló mis palabras.

Dobló, es decir, la calle duplicó las palabras al igual que el espejo duplica la imagen; pero también dobló las palabras para que sus extremos se acercaran entre cielo y suelo, como se juntan los bordes de una hoja de papel al doblarla. 
Al mismo tiempo, en sentido estricto se reafirma la condición de muerta que tiene la Muerte o la muerta (la estatua) dentro del mundo onírico en el que discurre el poema. $\mathrm{O}$ es posible, incluso, que la frase analizada exprese el deseo de este lúgubre personaje para que la dejen "descansar en paz", pues está agotada tras el acto carnal.

4. En el primero de sus "Epigramas de Boston", creaciones festivas que contrastan con la seriedad de otros poemas, Villaurrutia alude al nudismo en esa ciudad norteamericana e incluye nuevamente una dilogía:

\author{
El puritanismo \\ ha creado \\ un nuevo pecado: \\ el exceso de vestido, \\ que bien mirado \\ y por ser tan distinguido, \\ en nada se distingue del nudismo.
}

El "bien mirado" se refiere al hecho de observar algo atentamente, con minuciosidad. Mas la frase tiene otra acepción en tanto que lo "bien mirado" es sinónimo de "lo visto con agrado, con aprobación". Por último, también significa, en este caso, "pensado detenidamente, concienzudamente". En el mismo epigrama registramos al polisémico distinguido, que en este contexto ofrece las siguientes acepciones: "visto con claridad"; "distinto a otros, diferente"; "poseedor de elegancia, prestigio"; "notable".

5. Aludo a continuación a otro de sus irónicos "Epigramas de Boston", el número IV:

Como los rascacielos no son tradicionales, 
aquí los ponen por los suelos

horizontales

Si tomamos en cuenta que la frase "poner por los suelos" significa criticar algo o a alguien con dureza, resulta entonces que los edificios - rascacielos- son criticados en la capital de Massachussets. Pero también, - y aquí la fuente de la ironía- que en ese lugar son construidos "por los suelos", es decir, horizontalmente (cuando aquello que precisamente los caracteriza es su elevada edificación vertical).

6. En el poema titulado "Mudanza", Villaurrutia alude a la necesidad del cambio constante como opción única de supervivencia, y concluye con una frase disémica a modo de invitación:

El agua, sin quehacer,

se hastía.

La nube, de viajar, se cansa.

Por eso las nubes se exprimen...

y por eso crujen los muebles, y por eso se inclinan los cuadros.

¡Otra vida! ¡Otra vida!

Hagamos sitio a nuevos huéspedes:

echemos la casa por la ventana.

Esta expresión coloquial equivale a "gastar excesivamente", y el contexto del poema permite deducir que es lo que harán para festejar a "nuevos huéspedes". Sin embargo, aquí el significado primario al que nos remite el contexto, es el cambio de lugar que deberá sufrir la casa: se trata de tirarla, de literalmente sacarla por la ventana, y dejar ese sitio vacío a "nuevos huéspedes". 
7. Otra frase de carácter disémico aparece en el poema "Paradoja del miedo".

¿Cómo pensar, un instante siquiera, que el hombre mortal vive!

El hombre está muerto de miedo. de miedo mortal a la muerte.

Como frase hecha nos remite a la afirmación de que el ser humano se encuentra lleno de miedo, amedrentado, con respecto de la muerte. Pero, si es imposible al poeta pensar que el hombre mortal viva, le resulta posible confirmar que "está muerto".

8. En "Nocturno eterno" encontramos los siguientes versos:

o cuando de una boca que no existe sale un grito inaudito que nos echa a la cara su luz viva y se apaga y nos deja una ciega sordera

o cuando todo ha muerto tan dura y lentamente que da miedo alzar la voz y preguntar "quién vive"

“¿Quién vive?" pregunta obligada, desde tiempos remotos, con la que el vigilante nocturno hacía identificarse al sujeto con el que topaba; equivalente a "¿quién es usted?", es interrogación válida al encontrarse sorpresivamente con otro, dentro del tétrico ambiente a que alude el poema. Con todo, situada en contexto, la frase debe tomarse principalmente en su sentido literal, pues cabría cuestionarse “¿quién existe?”, “qquién vive aún?" dentro de un mundo en donde "todo ha muerto".

9. Pasaré ahora al "Nocturno de los Ángeles":

Se diría que las calles fluyen dulcemente en la noche. 
Las luces no son tan vivas que logren desvelar el secreto. el secreto que los hombres que van y vienen conocen, porque todos están en el secreto

La afirmación de que las luces no sean "tan vivas" es ambivalente, lo que se refuerza con el término desvelar: por una parte indica que no son "tan potentes" como para "impedir dormir" al secreto; y por otra, que tampoco son "tan listas", "tan inteligentes" como para conseguir "descifrar" el secreto.

10. En "Nocturno amor" el amante reclama celoso al amado que se entregue durante el sueño a un tercero.

Guardas el nombre de tu cómplice en los ojos pero encuentro tus párpados más duros que el silencio y antes que compartirlo matarías el goce de entregarte en el sueño con los ojos cerrados

Frase que supone el hacer algo "ciegamente", sin pensarlo. El amado, pues, se entrega a otro durante el sueño sin dudas, ni vacilaciones. Pero es fácil imaginar que si el acto sexual se produce en sueños, aquél tenga los ojos cerrados, pues se halla dormido.

11. Me referiré a continuación a la frase disémica "todo ha muerto" que aparece en dos de los nocturnos villaurrutianos:

porque la ausencia de tu sueño ha matado a la muerte y es tan grande mi frío que con calor nuevo abre mis ojos donde la sombra es más dura

y es un dolor inesperado y aún más frío y más fuego no ser sino la estatua que despierta en la alcoba de un mundo en donde todo ha muerto. ("Nocturno amor") 


\section{o cuando todo ha muerto}

tan dura y lentamente que da miedo alzar la voz y preguntar "quien vive"

("Nocturno eterno")

Construcciones que implican tanto que todo ha llegado a su término, ha finalizado; cuanto que todos los moradores del lúgubre escenario al que hacen referencia los poemas, dejaron ya de existir, con lo que el poeta es el único sobreviviente que permanece como estatua expectante, en el primer caso, y como noctámbulo aterrado, en el segundo.

\section{Un caso más aparece en "North Carolina Blues".}

\section{Confundidos \\ cuerpos y labios, \\ yo no me atrevería \\ a decir en la sombra: \\ Esta boca es la mía.}

Con base en el sentido usual del sintagma señalado, el protagonista "guarda silencio", debido a la situación comprometedora en la que se encuentra. Además, la frase retoma su sentido literal pues, aparentemente, por la proximidad en que se hallan las bocas durante ese íntimo encuentro, la oscuridad le imposibilita "distinguir sus labios de los del amante".

13. En "Décimas de nuestro amor" hay una pregunta angustiosa:

¿Por qué dejas entrever

una remota esperanza,

Y si no habrá amanecer

en mi noche interminable 
¿de qué sirve que yo hable

en el desierto. y que pida,

para reanimar mi vida,

remedio a lo irremediable?

La frase "hablar en el desierto" similar a "predicar en el desierto" significa en su sentido metafórico "hablar sin ser escuchado", ya que el amante sabe que todo acabará, pero además puede ser tomada en su sentido literal, pues se encuentra en el desierto, aislado. Registramos en este poema un término disémico: "reanimar". Si el amante ha quedado muerto ante el abandono del otro, es inútil que pida "revivir", "re-animar" su vida, es decir, volver a poner el alma en su cuerpo yerto. Pero reanimar es, asimismo, "levantar el ánimo", dejar a un lado la tristeza que le causa la indiferencia del otro.

14. En "Nocturno miedo" aparecen la frase hecha "cerrar los ojos" con valor disémico, así como el polisémico término desvelar:

Y no basta cerrar los ojos en la sombra

ni hundirlos en el sueño para no mirar, porque en la dura sombra y en la gruta del sueño la misma luz nocturna nos vuelve a desvelar

Dentro del ambiente onírico en el que transcurre el poema, hay una luz que en la oscuridad de la noche les "impide dormir", pero que hace también que se "preocupen", y que, además, "los desnuda", los deja al "descubierto" ante la duda de despertar sin vida. Ante ello, no basta "cerrar los ojos", y esto es tanto el "mantenerse ignorante" del suceso, cuanto "bajar los párpados" para conciliar el sueño.

Villaurrutia hace uso nuevamente del término desvelar, en "Nocturno de los Ángeles": 
las luces no son tan vivas que logren

desvelar el secreto.

con sólo dos de las acepciones señaladas: "las luces no pueden mantener despierto el secreto", y "las luces no logran descubrir, descifrar el secreto".

15. En el "Nocturno en que nada se oye" figura otra polisemia:

y mi voz ya no es mía

dentro del agua que no moja

dentro del aire de vidrio

dentro del fuego lívido que corta como el grito.

Corta, es decir, "divide", "fragmenta"; pero cortar, recordemos, es también "herir con el filo de un objeto", "traspasar la piel como lo hace el aire o el frío", y no deja, además, de hacer referencia al hecho de causar interrupción, como el grito que interrumpe el silencio.

16. Véanse ahora los versos siguientes:

El frío de acero

a mi mano ciega

armó con su daga,

mi mano acerada

encontró mi espalda.

("Nocturno sueño")

La mano "acerada" significa "la mano armada con la daga" (el acero), pero puede remitirnos, asimismo, a "la mano helada como el acero" y, como neologismo, a "la mano semejante a la cera" y como ella, blanquecina y pálida, pues se trata de la mano de un cadáver. 
17. Otro ejemplo, éste con carácter festivo, irónico, lo registramos en "North Carolina Blues":

¿Cómo decir

que la cara de un negro se ensombrece?

En North Carolina

Es decir, es exagerado afirmar que la faz de un hombre de piel negra se encuentra llena de sombras; se oscurece, tornándose negra. Ensombrecer, en su sentido metafórico, conlleva el sentido de "entristecer".

18. En el "Nocturno grito" se afirma:

Mi pecho estará vacío

y yo descorazonado

y serán mis manos duros

pulsos de mármol helado.

Si el pecho, literalmente, "está vacío", es de esperarse que no tenga corazón: des-corazonado ("sin corazón"); pero descorazonado significa también "desanimado" o "desalentado".

19. El término escala cobra valor disémico en dos poemas de Villaurrutia:

para salir en un momento tan lento

en un interminable descenso

sin brazos que tender

sin dedos para alcanzar la escala que cae de un

("Nocturno en que nada se oye")

piano invisible

Del barco del cielo

del papel pautado

caía la escala 
por donde mi cuerpo

bajaba

("Nocturno sueño")

En ellos escala tiene como primera acepción la de "escalera". En el primer poema el hombre va cayendo al vacío y sus dedos no pueden asirse de la escalera —escala_-; en el segundo, su cuerpo baja por la improvisada escalera celestial. Asimismo, las palabras piano y papel pautado en el primer y segundo poemas, respectivamente, permiten actualizar la otra significación de escala: "sucesión de las siete notas musicales", esto es, escala musical.

20. "Nocturno mar" aporta otro ejemplo disémico:

\section{Mar sin viento ni cielo, $\underline{\text { sin olas, desolado }}$}

donde desolado significa "desvastado, afligido"; pero Villaurrutia le otorga una segunda significación: des-olado: sin olas, neologismo que indica la ausencia de ondulaciones en ese mar.

21. En el poema titulado "Soneto del temor a Dios" aparece enredarte:

Es inútil mi fiebre de alcanzarte, mientras que tú, que todo lo puedes no vengas en mis redes a enredarte.

con doble acepción: "caer en las redes" en un sentido recto; y en el metafórico, "quedar atrapado ante los encantos de alguien".

22. Finalmente, en el ya citado poema "Nocturna rosa", tenemos un muy logrado juego de palabras a partir de varios términos disémicos: 


\section{Es la rosa encarnada de la boca}

la rosa vigilante, desvelada:

la rosa del insomnio desojada.

En el primer verso, el término encarnada aporta dos significados: la rosa es de color rojo (encarnado) como los labios de la boca; y la rosa encarnó, es decir, es la rosa hecha carne, transformada en carnosos labios. En el segundo de los versos citados, vigilante es a la vez: aquello "que se mantiene atento, que cuida y vigila"; y lo que "permanece en vigilia, despierto, en vela". La rosa desvelada es la que "no logra conciliar el sueño", la rosa "sin sosiego, preocupada" y la rosa "desnuda, descubierta". Por último, aparece la palabra desojada, a la que Villaurrutia, valiéndose de la homofonía, le da una doble connotación: crea el neologismo des-ojada /desoxáda/: "sin ojos" (utilizando el mismo procedimiento que aparece en des-olado), y nos remite también a des-(h)ojada / desoxáda/: "sin hojas". ${ }^{16}$

Es preciso anotar que la afición de Villaurrutia hacia los juegos de palabras basados en la polisemia está presente en gran cantidad de títulos tanto de sus poemas, cuanto de algunos ensayos y obras dramáticas.

A continuación menciono los títulos de poemas que pueden considerarse, semánticamente, bivalentes. "Mudanza": cambio

${ }^{16}$ Cabe hacer notar el ingenioso juego de correspondencia que existe entre los dos últimos versos citados, gracias a la polisemia de casi todos sus términos. Se afirma que la rosa está vigilante (a) y por mantenerse en vigilia esta desvelada (a) (sin poder dormir) y es la rosa del insomnio (no duerme) puesto que además se trata de una rosa de-sojada (a) (sin ojos). Por otra parte, la rosa se mantiene vigilante (b) (atenta, vigilando), pues está preocupada, existe algo que la inquieta, es decir, está desvelada (b) (algo le produce desvelos) y le produce insomnio por lo que permanece en vela vigilante (a). Además, el estar desojada (a) (sin ojos) es también la causa de que se mantenga vigilante (a) (en vela), vigilante (b) (atenta) y desvelada (a) (sin dormir); y como consecuencia del hecho de padecer insomnio, se deriva que amanezca desvelada (a) ( $\sin$ haber dormido). Encuentro, aún, una última relación: si la rosa está desojada (b) (sin hojas), estará también desnuda, descubierta, o sea, desvelada (c) (sin velos). 
o alteración del orden de los elementos; y traslado de domicilio, ya que como se recordará, la casa —en el poema-será "echada por la ventana". Nostalgia de la muerte (título del mejor de sus poemarios) presenta ambigüedad en cuanto a su significado: en una primera lectura manifiesta nostalgia, añoranza hacia la muerte, o hacia el hecho de morir; el poeta refleja así su pena por no estar muerto. Por otro lado, la preposición de indica semánticamente "propiedad, pertenencia, o posesión de algo"; así que también puede indicar que la Muerte (personificada) es la que padece la nostalgia de algo perdido... ¿acaso la vida? En "Nocturno de los Ángeles" se habla de seres que "han bajado a la tierra" por medio de "encarnaciones misteriosas", pero al final se menciona el nombre del lugar donde fue escrito el poema: Los Ángeles, California, lo que le otorga un segundo significado; ¿o se refiere acaso a los apuestos hombres llamados "Dick, Marvin, John, o Louis", que por su hermosura física merecen calificativo de "angelicales" en opinión del poeta?

La mayoría de los poemas de Nostalgia de la muerte incluye dentro de sus títulos el término "nocturno". Con este sustantivo se designa tanto en poesía como en música a un tipo particular de composición con cierto carácter melancólico ("Nocturnos" de Chopin, el celebre "Nocturno III" de José Asunción Silva, etc.). Nocturno, además, es un adjetivo que indica lo propio o relativo a la noche. Así, en los dos poemas titulados "Nocturno" aparece este carácter disémico. Si se observan los títulos de otros poemas encontraremos: "Nocturno miedo", "Nocturno grito", "Nocturno sueño", "Nocturno amor", "Nocturno preso", "Nocturno muerto" y "Nocturno mar" donde al sustantivo nocturno - referido al tipo de composición- se le añaden otros, que precisan el título de cada composición; y si tenemos en cuenta que nuestra lengua permite anteponer o posponer el adjetivo al sustantivo al que modifica directamente, puede concluirse que el término nocturno funciona como adjetivo (como 
en el caso de "Nocturna rosa") de los múltiples sustantivos a los que acompaña, y de esta forma los mencionados títulos equivaldrían, respectivamente, a miedo nocturno, grito nocturno, sueño nocturno, amor nocturno, etc. Por consiguiente, "Nocturno miedo" significa "el nocturno denominado miedo" y "el miedo que aparece en la noche"; "Nocturno grito", a la composición titulada "grito" y "el grito que surge en la noche"...

La disemia también se extiende a algunas de sus obras de teatro, ensayos y críticas. Cito varios ejemplos: El yerro candente, aquí la palabra candente es disémica: "metal calentado al rojo vivo"/ "grave, de mucha importancia"; por lo tanto el título significa al mismo tiempo "el error grave", y "el metal ardiente" gracias a la homofonía entre yerro /yéro/: falta, error; y hierro /yéro/: metal. En Invitación a la muerte, frase que sirve de título a otra de sus obras teatrales, ocurre un fenómeno semejante al de Nostalgia de la muerte, ¿se invita a la Muerte a acudir ante los personajes?, o $\measuredangle$ son ellos a quienes se invita a morir? ${ }^{17}$

"El renacimiento de Cervantes", frase que el propio Villaurrutia define como de "doble filo" pues significa tanto el hecho de que Cervantes vuelva a nacer, bajo la luz de nuevos estudios, y especialmente los de Américo Castro, cuanto a la influencia del Renacimiento - como época histórica y cultural — en la obra cervantina. En "Pintura sin mancha" se incluyen dos términos ambivalentes: pintura: "arte pictórico"/"cuadro o lienzo pintado"; sin mancha: "limpio"/"puro", "inmaculado", "intachable"; por lo que el título hace referencia a la pintura (arte) pura que guarda una estrecha relación con la poesía; y también a la pintura (cuadro) en la que el pincel no llegó a sobrepasar los límites señalados, y por tanto no manchó.

En un segundo grupo ejemplifico las dilogías que emergen en la poesía de Xavier Villaurrutia y que tienen como origen la homonimia.

17 Por otra parte, originalmente, el título en cuestión lo empleó un autor a quien Villaurrutia admiraba mucho: Jean Cocteau. 
A diferencia de las polisémicas, que aparecen en forma aislada y dentro de contextos ambiguos, las voces homónimas - como era de esperarse - se presentan agrupadas, es decir, figura un término o grupo fónico y muy cerca de él su homónimo, lo que permite contrastar ambos y actualizar el único significado posible para cada caso.

Como todos sabemos, la homonimia incluye tanto a la homofonía (u homonimia imperfecta, que es la identidad fónica entre dos o más palabras diferentes) como a la homografía (u homonimia perfecta, identidad gráfica $-\mathrm{y}$ por supuesto, también fónica - entre palabras diferentes).

El efecto, sin embargo, es desigual: cuando Villaurrutia opta por el uso de homónimos homógrafos, nos ofrece juegos de palabras con menor calidad, incluso fallidos, pues en gran medida $-\mathrm{y}$ aun contradiciéndose - el poeta se deja llevar por el "demonio de la analogía", al que tanto rehuye.

Por lo general, encontraremos que estos homógrafos son producto de la distinta función sintáctica que puede desempeñar una palabra.

Aporto varios ejemplos de juegos con homónimos homógrafos, en los cuales no me detendré, pues, repito, carecen de la calidad que se hace patente al emplear la polisemia y cuando, como posteriormente veremos, utiliza homónimos homófonos.

1. Ya inclinó su candor la mustia tarde

Yo no quiero llegar pronto ni tarde

("Yo no quiero")

2. Como la venda al brazo enfermo de un enfermo

("Nocturno muerto")

3. al cuerpo desvalido y muerto de algún muerto

("Nocturno muerto") 
4. la nada en la que no pasa nada

("Volver")

5. y solo sólo yo sé...

("Nocturno de la alcoba")

6. y por él sólo ser tu solo amante

("Soneto de la esperanza")

7. y cuando sueñan duermen no con los ángeles

Los Ángeles, California.

("Nocturno de los Ángeles")

8. la sed de mi sed

("Ya mi súplica es llanto")

9. Sacia su sed con una sed idéntica

("Nocturno amor")

10. Cuando en el sueño luchas con el ángel del sueño

("Nocturno de la alcoba")

11. No fuera amor el nuestro

¡No fuera nuestro amor!

("Nuestro amor")

Mejores resultados ha de obtener Villaurrutia, en mi opinión, con los siguientes versos:

12. Para darme muerte la muerte esperaba

("Nocturno sueño")

13. No es la rosa rosa

("Nocturna rosa")

14. Y es tan grande el silencio del silencio ("Nocturno eterno")

15. El juego más logrado mediante la homonimia perfecta lo registramos, sin duda, en "Nocturno en el que nada se oye", 
que alude a una mar en la que, a la par de que el poeta "olvida todo", resulta "imposible nadar" (seguramente porque éste ha dejado pies y brazos en la orilla):

el latido de un mar en el que no sé nada en el que no se nada

Como hemos advertido, al servirse de la homografía como semilla de juegos dilógicos el poeta obtiene magros resultados. Por contraste, mediante la homofonía Villaurrutia sí logrará grandes aciertos, al llevar de la mano sonidos iguales y múltiples significados para dar origen a una cascada de imágenes. Si la polisemia nos remitía al juego de espejos, la sucesión de imágenes acústicas análogas se asemejarán a ecos, procedimiento fónico que se enriquece con el seseo propio de nuestro dialecto mexicano. La serie de fonemas idénticos puede distribuirse en una, dos o más palabras, lo que revela, en algunos casos, agudo ingenio por parte del poeta y un extraordinario dominio del lenguaje.

El empleo homofónico corresponde precisamente a la figura llamada calambur o calembur que "constituye un tipo de juego de palabras [...que...] consiste en que dos frases se asemejen por el sonido y difieran por el sentido como en 'a ese Lopico lo pico' (de Góngora). Esta figura "se basa en una articulación distinta de los mismos elementos de la cadena sonora por lo que resultan diferentes unidades léxicas, es decir diferentes significantes $y$, naturalmente sus correspondientes distintos significados en que hay una aparente homonimia de oraciones completas". 18

Para una descripción detallada de este tipo de juego de palabras cito nuevamente a Helena Beristáin, quien acude a los conocidos versos del "Nocturno en el que nada se oye" ("y mi voz que madura"...), para ejemplificar precisamente al calembur:

${ }^{18}$ Beristáin, Diccionario de retórica y poética, p. 77. 
cada emisión de una serie fónica es segmentada de manera distinta que es fácil advertir por escrito, en la diferencia de los lexemas, pero que en el habla, aunque se observa una leve diferencia en la entonación y en las pausas, se escucha como una ambigüedad que propicia más de una interpretación, pues, debido a las varias posibilidades de segmentación del sonido, los significantes no continúan siendo claramente distintivos, ya que presentan una homofonía casi perfecta.

Ejemplifiquemos ahora esta figura retórica en la poesía de Villaurrutia y observemos su trascendencia:

1. En "Poesía" aparecen los siguientes versos:

estoy mirando mirarme por mil Argos, por mí largos segundos.

Las dos sucesiones idénticas de once fonemas, /poRmíláRgos /, nos remiten a dos significados distintos: "Veo como soy observado por un millar de Argos" (el mítico personaje griego poseedor de cien ojos); y "observo como me miro durante largos instantes".

2. En el mismo poema, al ser abandonado por la poesía, el protagonista se torna en un hombre desnudo:

\section{sin más pulso ni voz y sin más cara sin máscara...}

registramos aquí, dos emisiones construidas por diez fonemas idénticos distribuidos en el primer verso en tres palabras, y en el segundo, en dos, cuya única diferencia radica en el nivel suprasegmental, debido a un segundo acento que recibe la primera secuencia (/siNmáskára / = /siNmáskara /); y que en la dimensión semántica obliga al poeta a quedarse "sin otro rostro" y "sin careta alguna". 
3. Ejemplo semejante figura en "Nocturno miedo" en las preguntas que el poeta se hace:

\section{¿Quién medirá el espacio quién me dirá el momento}

Nuevamente diez fonemas que dan origen a dos series gemelas: /kiéNmedirá/ = /kiéNmedirá/ y dos significados: ¿quién se encargará de la comprobar la extensión del espacio? ¿quién podrá decirme la hora de mi muerte?

4. En el "Soneto del temor a Dios" registramos el siguiente juego homofónico por medio de las series: /nosepára/=/nósepára/= /nósépára/ con identidad segmental (Villaurrutia aprovecha la degeminación de los fonemas /s/ contiguos, por lo que al pronunciar las tres series contienen el mismo número de fonemas), pero no suprasegmental (el número de acentos se va incrementando en la siguiente serie) y con tres significados: nos separa (nos aleja), no se para (no se detiene), no sé para (ignora la finalidad):

la emanación fragante

de tu cuerpo intangible, nos separa

Atado estoy, inmóvil navegante,

¡y el río de la angustia no se para!

Y no sé para qué tendiendo redes...

5. "Nocturno de los Ángeles" nos muestra dos cadenas exactas $/ \mathrm{koNpaRtíRlo} /=/ \mathrm{koNpaRtíRlo} /$; las cuales revelan dos significados: "nada se ganaría con dividir el secreto en mil pedazos" y "dividirlo únicamente con la persona elegida":

Y nada se ganaría con partirlo 
en mil pedazos...

y compartirlo sólo con la persona elegida

6. La simplificación de fonemas idénticos contiguos, permite de nuevo a Villaurrutia crear dos líneas gemelas con significados diferentes en "Nocturno sueño". 19 Poema por demás interesante si atendemos a su estructura cerrada, en el que el Sueño, personificado según se infiere, entra en el espacio onírico para, posteriormente, salir de él convertido en un ave nocturna (acaso un vampiro) que con sus alas clausura ese mundo inasequible.

Comienza con estos dos versos:

Abría las salas
profundas el sueño

Y termina:

cerraba las alas

profundas el sueño

7. Concluyo este análisis con el copiosamente apuntado, por todos los estudiosos de Villaurrutia, "Nocturno en que nada se oye", en el cual el poeta, partiendo de una sucesión de idénticos grupos de fonemas (sólo la cuarta serie posee un acento más), crea cuatro significados distintos, que al igual que toda una serie de imágenes se van encadenando para proyectar un eco "angustiado" y angustioso que repite incesantemente el reflejo de un cadáver frente al espejo:

${ }^{19}$ En el VIII de los "Epigramas de Boston" surge otro juego homofónico, aunque con un sentido jocoso, ya explicado por César Rodríguez Chicharro.

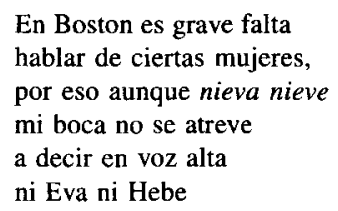


y mi voz que madura /imibóskemadúra/

y mi voz quemadura /imibóskemadúra/

y mi bosque madura /imibóskemadúra/

y mi voz quema dura /imibóskémadúra/

Casi al final, registramos en el mismo Nocturno, los siguientes versos:

Siento caer fuera de mí la red de mis nervios mas huye todo como el pez que se da cuenta * hasta ciento caer en el pulso de mis sienes* muda telegrafía a la que nadie responde

en los que podemos advertir que ciento /siéNto/ es homófono con respecto de "siento" /siéNto/ "caer fuera", pero es también disémico dentro del contexto donde se encuentra, pues si ignoramos su representación ortográfica, es decir, si no leemos el verso y únicamente lo escuchamos, significa tanto sentir como el centenar de pulsaciones emitidas desde el metafórico telégrafo. Existen además otros dos términos (*) que refuerzan el juego: cuenta que puede referirse tanto al hecho de enumerar (contar) las pulsaciones, como a tener conciencia (darse cuenta). La otra palabra es sienes, que a pesar de no ser ambivalente en este contexto, sí es homófono dentro de nuestra norma, por lo que representa aquí un juego implícito (sienes/ cienes) que alude tanto al sentir como a la idea de centenar.

Tras este recuento hemos podido constatar cómo, a través de la poesía y sus juegos, Xavier Villaurrutia transforma la polisemia y la homofonía, fenómenos inherentes a la lengua, en el medio idóneo para aprehender tanto el hermético mundo del sueño - ora el pasajero, ora el eterno-, cuanto los velados confines del amor, e inclusive acceder al terreno de lo irónico, 
dentro de un enigmático universo paralelo en el que se entrelazan ecos y espejos.

\section{BIBLIOGRAFÍA}

BAEz, Gloria, Recursos estilísticos en la poesía de Xavier Villaurrutia, Tesis inédita.

BERISTÁIn, Helena, Diccionario de retórica y poética, México, Porrúa, $8^{a}$ ed. corr. y aum., [1985] 1997.

Blanco, José Joaquín, Crónica de la poesía mexicana, Guadalajara, Departamento de Bellas Artes, 1977 (Col. Textos Latinoamericanos).

DAUSTER, Frank, Ensayos sobre poesía mexicana. Asedio a los Contemporáneos, México, Ed. de Andrea, 1963 (Col. Studium, 41).

- Xavier Villaurrutia, Nueva York, Twayne Publishers, 1971.

Forster, Merlin H., Los Contemporáneos: 1920-1932. Perfil de un experimento vanguardista mexicano, México, Ed. de Andrea, 1964 (Col. Studium, 46).

Moretta, Eugène L., La poesía de Xavier Villaurrutia, México, Fondo de Cultura Económica, 1976 (Col. Lengua y Estudios Literarios).

PAZ, Octavio, Xavier Villaurrutia en persona y en obra, México, Fondo de Cultura Económica, 1978.

Rodríguez Chicharro, César, "Disemia y paronomasia en la poesía de Xavier Villaurrutia. Ejemplos", La Palabra y el Hombre, Xalapa, núm. 30, abril-junio de 1964, pp. 81-90.

SHERIDAN, Guillermo, Los contemporáneos ayer, México, Fondo de Cultura Económica, 1993.

Todorov, Tzvetan, Literatura y significación, Barcelona, Planeta 1967 (Col. Ensayos).

Ullmann, Stephen, Semántica, Madrid, Aguilar, 1965.

Villaurrutia, Xavier, Obras, prólogo de Alí Chumacero, recopilación de Miguel Capistrán, Alí Chumacero y Luis Mario Schneider, bibliografía de Luis Mario Schneider, México, Fondo de Cultura Económica, 1974 (Col. Letras Mexicanas). 